\title{
An Empirical Study of Memetics Applied in Optimizing SLT
}

\author{
Lihua Zhu \\ School of Foreign Languages, Tianjin University of Commerce, 300134, China \\ Email: 1hzhu@126.com
}

\begin{abstract}
Memetics, a new branch of study researching into the replicate, proliferation and evolution of meme based on Neo-Darwinism, probes dynamically into the cultural medium: meme, in the perspective of culture evolution, information intercommunion and thought contagion. Meme, depositing in individual's memory as the replicative gene, can be replicated in another individual's memory so as to remodel the other individual's thought, action and even consciousness by means of imitating and replicating. As the hosts to meme, the individuals continue their proliferating and self-proliferating among the whole community and result in enhancing the evolution of society, culture and language. The paper attempts to give a general review of memetics studies and then make an investigation into the theory models and practical significance of memetics applied in optimizing SLT from the aspect of imitation, taking culture evolution, information intercommunion and thought contagion as the study module, social-linguistics and pragmatics as the theory models.
\end{abstract}

Index Terms-memetics, teaching strategies, imitation, thought contagion

\section{INTRODUCTION}

The term "meme", the unit of cultural evolution and the cultural equivalent of gene, was firstly put forward by the biologist Richard Dawkins in the last chapter of his best seller treatise The Selfish Gene, in order to explain the amazing similar phenomenon between different cultures, and meanwhile some examples of memes were enumerated: tunes, ideas, catch-phrases, clothes fashions, and ways of making pots or of building arches. Meanwhile, Dawkins explained that the word was borrowed from the Greek word "mimeme" and abbreviated to the monosyllable "meme" whose pronunciation sounds like gene. Just as genes propagate themselves in the gene pool by leading from body to body via sperm or eggs, memes propagate them in the meme pool by leaping from brain to brain via a process which, in the broad sense, can be called imitation.

The term "meme" is actually defined by dozens of scholars in various ways as: a unit of imitation, a unit of information residing in a brain (Dawkins, 1976), culturally transmitted instructions, any permanent pattern of matter or information produced by an act of human intentionality, roughly equivalent to ideas or representations, a unit of information in a mind whose existence influences events such that copies of itself get created in other minds, actively contagious ideas, a mental representation, a self-replicating element of culture passed on by imitation (Oxford Language Dictionary), etc. Besides, meme is defined as having intimate relations with memetic and memory, rhyming with "dream" in encyclopedia; "American Heritage Dictionary" defines it as "A unit of cultural information, such as a cultural practice or idea, that is transmitted verbally or by repeated action from one mind to another." In consequence of these overflowing definitions, the word becomes almost meaningless, when applied to the instructions in brains, information, behaviour, words, mental states, books and all kinds of cultural artifacts without consistency, and that is why a scientific study of meme, memetics, is required urgently.

Memetics, a branch of scientific study of meme, a new theory expounding the law of culture evolution on the basis of Neo-Darwinism, the importance of which is becoming conspicuous day by day in the research of language information transmission, presentation imitation and inter-contagion of thoughts.

\section{A. The Study of Meme across the World}

At present, quite a few of scholars are engaging in the research on Memetics at multi-levels and in multi-perspectives. Memetics center, memetics webpage and periodical of memetics such as "Journal of Memetics" have been established. There are several groups of scholars who are for memetics: a) From the point of view of thought contagion. Paul Marsden (1998) and Derek Gatherer (2001) take it as an idea that is replicated by parasitically infecting human minds and altering their behavior, causing them to propagate the ideas. William S. Burroughs (1999) also supports this standpoint and advances that "Language is a virus". b) From semiotic point of view. Bio-anthropologist Deason thinks that a meme is regarded as a sign or, exactly, as a carrier of a sign that replicates by infecting human minds and altering their behavior, similar to the way a virus reproduces by hijacking the DNA of a bacterium. Unlike a virus, however, which is encoded in DNA molecules, a meme is nothing more than a sign that induces people to repeat its pattern. c) From the view of information processing. The philosopher Dennett (1991) and Lynch (1991) understand a meme as an information pattern held in an individual's memory, which is capable of being copied to another individual's memory. d) 
From the viewpoint of cultural evolution. The sociologist Edward O. Wilson (1998), Gabora (1997) and Marion Blute (2003) regard meme as a unit of the socio-cultural evolution stored in mind with cultural or social phenotypes. For them, memes taking the role of genes as the second type of replicators are embodied in individual brains or social organizations or stored in books, computers and other knowledge media. And other scholars devote themselves to memetics, such as Nick Rose (2004) who combines memetics with neurology and ecology in order to study the biological features of meme.

In recent years, the interest in memetics research is raised to a new climax, which is symbolized by The Meme Machine written by Susan Blackmore and published from Oxford University Press in January of 1999. The Meme Machine summarizes the development of memetics during these years and announces the new connotation of its conception.

Although most of the scholars admit that the memetics play an inestimable role in the way of lowing to reveal the profound mystery of culture, they also take some questions about concrete manipulate of this theory, such as the copying-fidelity and the distinction between meme and its phenotype.

\section{B. The Study of Meme in China}

In China, however, memetics is still a new subject. At present, only a few scholars, such as He Ziran, Wang Bi, Xie Chaoqun, He Xuelin and Han Jianghong, are committing themselves to this study and writing some articles about memetics. And some of them are researching into the application of memetics in some of the foreign language teaching strategies: the grammar-translation method, direct method, the oral approach and the situational language teaching (SLT), communicative approach, cognitive approach, total physical response, etc.

\section{TheOretical Models OF Memetics Optimizing SLT}

Chen Linxia and He Ziran (2006) argued that it was the memetics who introduced the idea of information intercommunion into language teaching. By means of memetics, as a kind of medium, Words can be replicated, and meanwhile even the mode of creating words can be replicated as well. Thus the interactive mode between people and languages is formed, and the change and development of languages can be explored. Memetics has a capacity of enriching the theory of verbal communication, providing new way of thinking for the research on the verbal communication and explaining more reasonably the verbal and behavioral communication character in Internet. The phenomenon of duplication and transmission of meme can illustrate the regular pattern of reproduction, evolution of meme, as well as the appearance and disappearance of language itself. Memetics not only provides the model of cultural information transmission, which is an assistance of interpreting the inherited similarities of various cultures, but also proposes the view of meme imitating, which is of great theoretical and practical significance in the perspective of cultural transmission, language teaching and translatology research. Their paper also reveals the important influence of Memetics research upon language research, and has thus laid the theoretical foundation of the study of Memetics and language as well as the study of language teaching reform. Under the guiding of memetics, some traditional teaching methods, which were considered irrational and undesirable in the past, now can be reevaluated, reinstated and even re-advocated. The positive significance of imitation in language learning is being paid more and more attentions to and there is no doubt that the course of learning language is the course of replicating and transmitting memes. And that's why it is firmly believed that memetics will offer more and more helps and enlightenments to foreign language teaching.

The Situational Language Teaching(SLT) is firstly designed by British applied linguists, based on the structuralism, and its basic approaches are setting situations, inputting information, transmitting culture and infecting thoughts (exerting a subtle influence on one's thinking), as well as the error correction and evaluations through observing and the information feedback under a rational monitoring mode. The Situational Language Teaching (SLT) has a strong dependence on the textbook and those audio and video teaching materials, taking the pictures, cards, DVDs, and the Internet media technology for its assistant tools. Among SLT patterns, imitation is a crucial one in acquiring knowledge, and is also the key content of the research on Memetics, functioning as the combinative relationship between acquiring knowledge and studying Memetics. Consequently, from the above two aspects: the imitation in setting situation and imitation in imputing information, this paper will attempts to make an empirical study of memetics applied in optimizing SLT in three different perspectives: information replication, culture transmission and thoughts contagion.

\section{A. Situation Setting and Imitation}

Memetic provides a new perspective for the research of language teaching methodology, which is an important theoretical basis in optimize SLT. The difficult points in the research are to solve the differences between imitation and individual thought patterns, mechanical imitation and active construction, etc.

Language acquisition can't do without language context. The situational context of British structuralism is in accordance with Halliday (1994) systemic functional linguistic context. As the environment of language use, context connects the language form with its situation, and thus yields the context meaning, and traditionally it is categorized into situational context and cultural context, the former referring to the specific meaning in specific context, and the latter regarding the language system of social environment as a context, constructing associative meaning and cultural 
meaning. The input of the context theory provides a vital theoretical basis for setting the reasonable situation. In the specific situation, learners can acquire knowledge by means of imitation, imagination, inference in accordance with the situation for the purpose of obtaining knowledge. According to memetics, the life span of meme can be divided into four sequential processes: assimilation, retention, expression, and transportation. Assimilation refers to the first process in which memes are noticed, understood, and accepted by its host. Retention refers the period when memes remain in the memory and possess a strong intention of selection, as a result, only the few memes have the opportunity to survive. Expression is the third process in which memes must come out from the memetic storeroom in the memory when they exchange with other individuals, giving an access to a perceived material configuration. Transmission, an expansion of expression, refers to the last process in which memes expand the scope of transmission by means of varieties of carriers. In this particular situation, the classroom, learners are the hosts, who firstly observe the setting situation, comprehend and accept it, and then form the memory. Finally through the communication with teachers and classmates, they can demonstrate it, and thus make the knowledge spread.

A situation setting is usually carried out at four levels: a) Setting concrete situation. The specific character, the real event in the nature are truly recorded by means of multimedia technology, and are presented intuitively in front of the learners according to the teaching needs so as to "Set the situations, inspire the thinking". In this concrete situation, learners may develop their language sense unconsciously through repeated imitation, practice and communication. b) Setting associative situation. The method is to connect the related knowledge by hyper link, and form the knowledge system so as to prolong the time span in which the memory and the extended memes (i.e. the acquired knowledge) can live a longer life. Take the word "perspective" for example. When learning the word "perspective", learners can use hyper link to link up the same sort of word including its synonyms and antonyms, together with the compound words and phrases deriving from the same root. Setting the associative situation, learners can associate more than 40 such words sharing the related meaning "look" as "aspect", "respect", "inspect", "prospective", "prospect", "spectate", "specter", etc. And in this way, learners can enrich their vocabulary quickly and easily. c) Setting inferential situation. By using the related information from the corpus, learners can construct their own thinking model positively by means of observation, inference and conclusion. Take the following for example. "A child is a child, how can they not make a mistake?" "Rich men are rich men, how thick are the necklaces on their necks?" This rhetoric device "tautology" is also a kind of meme. Learners can perceive and learn the cognitive mechanism through observing, inferring and concluding its rules. d) Setting the pragmatic situation. One sentence or one word may have different meanings in different situations. Let's make an analysis of the meme: "You are really a kind-hearted soul", in the social pragmatic perspective. Firstly, the meme "You are really a kind-hearted soul" can be interpreted as a kind of praise following The Politeness Principle (Levinson, 1983). Secondly, assume these words from a jealous official wife. The implication may be "praise" with quotation mark, because what the wife hates most is her husband always helping his female subordinates too enthusiastically. Learners can take advantage of their own cognitive model to selectively replicate the reasonable and meaningful memes according to the proper context, such as "You are really Chen Shimei (an evil Chinese classic image, tending to murder his wife and two children so as to get married with the princess)", "You are really Hamlet", "You are really Pandora's Box", "You really are Quick Tongue Sister" and so on.

\section{B. Information Input and Imitation}

The Situational Language Teaching needs not only a large amount of teaching materials, but also a great deal of information. Memetics argues that imitation is one of the most important natures of human beings. The results of consulting the magazine --- "Journal of Memetics" on line, reveal that the researching scope of meme not only includes the cultural transmission and thought contagion, but also contains the language teaching mode. It is cultural unit, informational unit and mnemon. The main approach is achieved by situational imitation, informational replication, thought contagion and cultural transmission. In fact, to mnemon, the process of meme's imitation and replication is equal to that of acquiring knowledge and learning. Therefore, it's necessary to make full use of the computer which has a big storage and high speed so as to optimize a profusion of teaching information, handle it accurately, and then provide it to learners in time. And that may speed up the teaching process, enlarge the lesson's capability, widen the information and enhance the teaching quality in the fixed time. After replicating a mass of information and stocking it in their brains, the learners can constantly release the replicated information, or the memes, and let them spread by means of communication. And in this way, the knowledge is spread and the teaching purpose is thus achieved. Indubitably, the methodology guided by the theory of memetics can break through the traditional process of Stimulation-Reaction(S-R), prompt the mutual effects between the new and old information, and construct the individual's meaning by the process of assimilation and acclimation incessantly. In the end, learners are able to acquire new knowledge by analyzing and discriminating new information, in the four processes of assimilation, retention, expression and transmission.

\section{An Empirical Study of Memetics APPlied in Optimizing SLT (ExPERIMENT, Test AND Evaluation)}

Test and evaluation are two important means of testing and evaluating theoretical model and guiding teaching practice. Data collection and data analysis helps to make a dynamic analysis of the teacher's teaching and the learners' learning as well as the feedback information. Testing and evaluation system mainly includes achievement test, proficiency test and language test. According to the theoretical model of test and evaluation grades, the experimental 
classes and control classes are classified, and learners are set to take tests in a specific situation (multimedia classroom), with the results of the test data to evaluate the reliability and validity of applying memetics in language teaching. And the experimental results can provide an important theoretical basis for the design and improvement of SLT. Paper testing is the main approach to the empirical study.

\section{A. Design of the Experiment}

Target of investigation and examinee: undergraduates of English Department, from freshman to senior including Class One and Class Two. Setting of the experimental group and the control group: four Class Ones from the four grades as the experimental group; the other four Class Twos as the control group. The classes are originally divided by English Department, based on their university entrance examination scores, each class with basically equal scores, equal textbook, so that the experiment can be of comparability and serviceability. The test corpus, test methods and test purpose, see table 1:

TABLE 1

CONTENT IN CLASSROOM EXPERIMENTS

\begin{tabular}{|l|l|l|l|}
\hline Test Objects & Test Corpus & Test Methods & Test Purposes \\
\hline \multirow{5}{*}{$\begin{array}{l}\text { Experimental } \\
\text { Group }\end{array}$} & 50 Names of Animals \& & 1. Spelling & $\begin{array}{l}\text { Information } \\
\text { Replication }\end{array}$ \\
\cline { 2 - 4 } & 50 Pictures of Fruits & 2. Closed Exam & Cultural \\
& 50 Sentences of Cultural Communication From & 1. Filling Blanks & Transmission \\
\cline { 2 - 4 } & Network; Displaying Context by Flash & 2. Closed Exam & Thought \\
\cline { 2 - 5 } & 50 Terms from "Pragmatics" "Rhetoric"; Audio Data & 1. Spelling & Contagion \\
\hline Control group & Adopting Traditional Teaching Methodology & Same Methods & Same Purposes \\
\hline
\end{tabular}

\section{B. Steps of the Experiment}

Class instruction and closed exam. Firstly, test the Experimental classes of the four grades three times, and 2 hours each time. In the first hour, the experimental group is taught with experimental teaching method, while the control group with traditional mode. And in the second hour, both of the two groups take closed exams simultaneously. The purpose of the 3 times exams is to test the learners' validity of acquiring and replicating information under the sensory stimulation in hearing, vision and so on, to test the reliability of the information fidelity, and to test the extent of culture acquisition in communication and thoughts contagion in language teaching and learning. The first test consists of 100 questions with the score of 100 points. Every kind of animal name treated as a question is inscribed as 1 point. The second and third test each consists of 50 questions each of which is 2 points inscribed as 100 points. And then each of the student's average score is calculated as the data of further research. After a month, the second phase of exam is conducted of which the testing methods and contents are the same as the first time. This time direct exams are taken without the experimental teaching in order to detect the length of the time of the acquired information and thoughts stored in the learners' minds of obtained by the experimental teaching. The supposition is determined the higher scores, that is to say, the longer the memory information storage time is, the better the study effect is.

\section{Statistical Analysis of Experimental Data}

Through the statistical results of experimental classes and control classes, we have performed experiments for three times, from the information replication, cultural evolution and thought contagion, to test the reliability and validity of memetics applying to the situational language teaching (see table 2).

TABLE 2

TEST STATISTICS OF THE FIRST PHASE

\begin{tabular}{|l|l|l|l|l|l|}
\hline \multirow{2}{*}{ Class } & \multirow{2}{*}{ Students } & \multicolumn{3}{|c|}{ Average scores } & Average scores \\
\cline { 3 - 6 } & & 1 st & 2nd & 3rd & 3 times \\
\hline $03-1$ & 26 & 84 & 81 & 78 & 81 \\
$03-2$ & 27 & 73.5 & 70.5 & 65 & 69.7 \\
\hline $04-1$ & 20 & 79 & 80.5 & 75.5 & 78.3 \\
$04-2$ & 22 & 70 & 70.5 & 68.5 & 69.7 \\
\hline $05-1$ & 24 & 75 & 77.5 & 72 & 74.8 \\
$05-2$ & 23 & 68.5 & 65 & 66.5 & 66.7 \\
\hline $06-1$ & 25 & 74.5 & 77 & 74 & 75 \\
$06-2$ & 24 & 68 & 66.5 & 60.5 & 65 \\
\hline
\end{tabular}

Table 2 shows the examinees' paper scores of the four grades, eight classes. In these 3 exams, scores of the four experimental classes are generally nearly 10 percentage points higher than that of the control classes, and between Grade03 and Grade06, the difference value $\geq 10$; between Grade04 and 05 , the difference value is also 8.6 and 8.1 respectively, $\cong 10$, showing a significant difference. According to the first information replication exam, the scores of the four experimental classes are 84, 79, 75 and 74.5 respectively, while the scores of the control class are only 73.5, 70, 68.5 and 68. Theses remarkable differences indicate that setting situational context (images display, situation setting) 
can stimulate the visual senses, enlarge the students' vocabulary and promote the learning of language, especially in the fields of memorizing those specific material nouns, such as the names of animals, plants and so on. In the perspective of cultural transmission and thought contagion, language learners are set in the cultural context, with the aid of multimedia technology, through reading, voicing, imitating, to infer the associative meaning and cultural meaning based on their acquired existing knowledge in order to improve their grades. Compared with the control group, the scores of the experimental group in the last two phases are $615.6(81+78+80.5+75.5+77.5+78.3+72+74.8)$, which has remarkable differences and is much higher than the scores of the control group which are 533.

TABLE 3

DIFFERENCES OF TWO GROUPS IN TWO PHRASES

\begin{tabular}{|l|l|l|l|l|l|}
\hline Time/Difference & Grade03 & Grade04 & Grade05 & Grade06 & Average Difference \\
\hline Difference1 & 10.7 & 8.6 & 8.1 & 10 & 9.35 \\
\hline Difference2 & 11.3 & 8.9 & 8.5 & 10.4 & 9.78 \\
\hline
\end{tabular}

Since the testing method and contents of in the last two phases are similar to the first phase, the specific test table is omitted and only the differences of the four grade between the experimental group and control group are retained, in order to carry on the contrast research of the two stages (see table 3).

Table 3 proves the more remarkable testing differences between the experimental group and the control group in the second phase a month later. The value of difference is 9.78, 0.43(9.78-9.35) higher than that in the first phase, illustrating that the combination of Memotics and SLT can not only improve the learning results remarkably but also store the gained meme (mnemon and theories) longer in the learners' brain, and that the longer the meme is stored in brain, the better the learning effect will be.

\section{CONCLUSION}

The above empirical study makes scientific research into the theory models and practical significance of memetics applied in optimizing SLT from the aspect of imitation, taking culture evolution, information intercommunion and thought contagion as the study module, social-linguistics and pragmatics as the theory models. The results clearly show its significance and its positive meanings in promoting language teaching methodology and language teaching reform. Under the guiding of memetics, some traditional teaching methods which were thought irrational and undesirable in the past, now maybe can be reevaluated, even be reinstated and be re-advocated. And we can firmly believe that memetics will offer foreign language teaching more help and enlightenments, though some of the theories and research methods are not so mature, and require further improvement.

\section{REFERENCES}

[1] Aunger, R. (ed.). (2000). Darwinizing Culture: The Status of Memetics as a Science. New York: Oxford University Press.

[2] Baldassarre, G. (2001). Cultural evolution of "guiding criteria" and behaviour in a population of neural-network agents. Journal of Memetics, http://jom-emit.cfpm.org//2010.10.

[3] Ball, J. A. (1984). Memes as Replicators. Ethology and Sociobiology 5, 145-151.

[4] Basalla, G. (1988). The Evolution of Technology. Cambridge: Cambridge University Press.

[5] Blackmore, S. (1999). The Meme Machine. Oxford: Oxford University Press.

[6] Blum, H. F. (1955). Times Arrow and Evolution. Princeton: Princeton University Press.

[7] Blute, M. (2002). The Evolutionary Ecology of Science. Journal of Memetics-Evolutionary Models of Information Transmission 17, 7-12.

[8] Bowker, J. (1995). Is God A Virus? Genes, Culture and Religion. London: SPCK.

[9] Butler, S. (1872). Erewhon: or Over the Range. London: Jonathan Cape.

[10] Burhoe, R W. (1967). Five steps in the Evolution of Mans Knowledge of Good and Evil. Zygon2, 77-96.

[11] Burroughs, W. (1999). Word Virus: The William Burroughs Reader. NY: Flamingo.

[12] Chaoqun, X., Ziran, H \& Susan, B. (2007). The Misunderstood Memes. Foreign Language Education3, 11-15.

[13] Coady J, \& Huckin T. (1997). Second Language Acquisition. Cambridge: Cambridge University Press.

[14] Dawkins, R. (1976). The Selfish Gene. New York: Oxford University Press.

[15] Dawkins, R. (1993). Viruses of the Mind, in Dahlbom B. (ed.) Dennett and his Critics: Demystifying mind. Oxford: Blackwell.

[16] Deacon, T. W. (1999). Memes as Signs. The Semiotic Review of Books7, 21-25.

[17] Gatherer, D. (2011). Modeling the effects of memetic taboos on genetic homosexuality. Journal of Memetics, http://jom-emit.cfpm.org//2010.10.

[18] Dennett, D. (1991). Consciousness Explained. New York: Little, Brown \& Co.

[19] Dennett, D. C. (1995). Darwin's Dangerous Idea: Evolution and the Meanings of Life. London: Allen Lane \& Penguin.

[20] Eldredge, N. (1995). Reinventing Darwin: The Great Evolutionary Debate. New York: John Wiley.

[21] Gamst, C. G. \& Norbeck, E. (1976). Ideas of Culture: Sources and Uses. New York: Holt, Rinehart and Winston.

[22] Gabora, L. (1997). The origin and evolution of culture and creativity. Journal of Memetics, http://jom-emit.cfpm.org//2010.10.

[23] Grice, P. (2002). Studies in the Way of Words. Beijing: FLTRP and Harvard University Press.

[24] Hull, D. L. (1988). Science as a Process: An Evolutionary Account of the Social and Conceptual Development of Science. Chicago: Chicago University Press.

[25] Linxia, C. \& Ziran, H. (2006). Analysis of memes in language. Foreign Language Teaching and Research2, 114-118. 
[26] Locke, J. (1690). An essay concerning human understanding. Oxford: Oxford University Press.

[27] Lumsden, C. J. \& Wilson, E. O. (1983). Promethean Fire: Reflections on the Origin of Mind. Harvard: Harvard University Press.

[28] Lynch, A. (1996). Thought Contagion: How Belief Spreads through a Society. New York: Basic Books.

[29] Marsden, P.S. (1998). Operationalising memetics - Suicide, the Werther effect, and the work of David P. Phillips. Proceedings of the 15th International Congress on Cybernetics, Namur, Belgium.

[30] O’Malley, J. M. \& Chanot, A. U. (1990). Learning Strategies in Second Language Acquisition. Cambridge: Cambridge University Press.

[31] Rose, N. (1997). Lifelines: Biology, Freedom, Determinism. London: Penguin.

[32] Sargant, W. (1957). Battle for the Mind. London: Heinemann.

[33] Shaolian, C. (2006). Memetics and Language Variations. Journal of Guangdong University of Foreign Studies3, 31-35.

[34] Steadman, P. (1979). The Evolution of Designs: Biological analogy in architecture and the applied arts. Cambridge: Cambridge University Press.

[35] Wardhaugh, R. (2000). An Introduction to Sociolinguistics. Beijing: Foreign Language Teaching and Research Press \& Blackwell Publishers Ltd.

[36] Yu, G. (2008). Reconsideration of the Character and Status of Chinese Modern Translated Literature. Journal of Chinese Modern Literature Research 3, 160-170.

Lihua Zhu was born in Shaanxi Province in 1968. He received his M.A. degree in Linguistics from Northwest Normal University, China in 2000. He is currently an associate professor and tutor for graduates in School of Foreign Languages, Tianjin University of Commerce. His research interests include translation and literature. 